\title{
Cascade Model for Online Discussion Boards in an E-Learning Environment
}

\author{
$\underline{\text { doi:10.3991/ijet.v5i1.1130 }}$ \\ V. Kumar \\ Medical College of GA, Augusta, GA, USA
}

\begin{abstract}
This report is an outcome of five years of higher education teaching and managing groups of students in an online learning environment. Some course management software allow users to create groups and add different links within each group that has been created by e-moderators. Distinct platforms with various sections can be formed within those links for any given project. Students, as well as instructors, can manage the project for 6 to 8 weeks, cascading one discussion board into one or multiple platforms. This provides better understanding of the project material due to the step-by-step layout of a given exercise, leading to increased group management and greater communication among the e-moderators, group leaders and group members. This report provides the step-by-step procedure for cascading one discussion board into various platforms to manage online group projects and provide a more controlled online environment for students in higher education.
\end{abstract}

Index Terms-Cascade Model, Course Management Software, E-moderator, Group Management, Online Discussion Boards.

\section{INTRODUCTION}

Online teaching and learning is a growing field and continues to connect students and faculty all around the world. The format of online group management is different from those utilized in the traditional classroom setting. E-moderators demonstrate the willingness and ability to solve problems at a distance and communicate with students daily.

Group projects are an important part of online courses in higher education. Online courses need a format for group management that is different from those utilized in the traditional classroom setting or face-to-face project solving. A few of the course management systems software, such as e-College and Blackboard, provide a tab called 'Groups' for group-project activities within the course navigation bar. For example, in e-College learning software the 'Group' tab gives entry to only one preformed group discussion board. After entering into Groups tab, one discussion board can be sectioned into many on a weekly schedule. This group management model is cascaded into seven sections. These sections of a group discussion board can be titled by the week. In online courses where students have to solve a project question via communication, participation, collaboration, and forming teams, a well-formatted discussion board is required.

The learning experience of online teaching and handling group projects is how to provide weekly instructions to the students to run the assigned project, and ways to keep online learners on topic during asynchronous discus- sion. This experiment of cascading discussion board week-by-week provides a format that gives a better outcome compared to email solutions, chat, or space creation for the group discussion.

\section{METHODS}

Within an online course, a group project exercise that runs for about 6-9 weeks has a much shorter life cycle than that of the Project Management Life Cycle [1]. For example, if a class of 20 students is divided equally into four groups, then cascading of the weekly boards are done as follows (Fig.1):

Week-1 Introduction and group leader election: Initially, students are usually nervous and overwhelmed working on project exercises online. During the first week of a project, each member of the group introduces himself or herself. The e-moderator should try to get familiar with the group members and work with them on electing a leader of the group for week-to-week leadership. The emoderator will also set up a welcome message and a thread for the group to start communication on the discussion board and intervene to clarify various platforms and threads each week.

Week-2 Declaration of the project exercise and general policies of the online group participation: During week-2, the e-moderator will declare the project exercise question and the general policies or guidelines for participating in the online group project. The elected leader will initiate the discussion to understand the question. Each member will look for the resources related to asked question and post his/her searches within first three days of the week. The discussion will continue for the remaining days of the week. The leader will summarize the weekly activity and post it at end of the each week. The e-moderator will clarify the task, the timescale, and also the form of the presentation on the discussion board. Each member of the group must join in and participate in the discussion throughout the week. A crosscheck is required for late joiners.

Week-3 Define project scope, planning, sources, online discussion \& weekly report: In week-3, the leader will initiate the discussion defining the scope of the exercise. The members will participate in the follow-on discussion throughout the week to discuss on the scope, planning, and the solution to the problem. The e-moderator will set up a thread for the group and intervene to clarify, if necessary.

Week-4 Work breakdown structure, online discussion \& weekly report: The leader will divide the work amongst the members of the group for them to follow. The week's discussion goes on while the leader divides the work, 


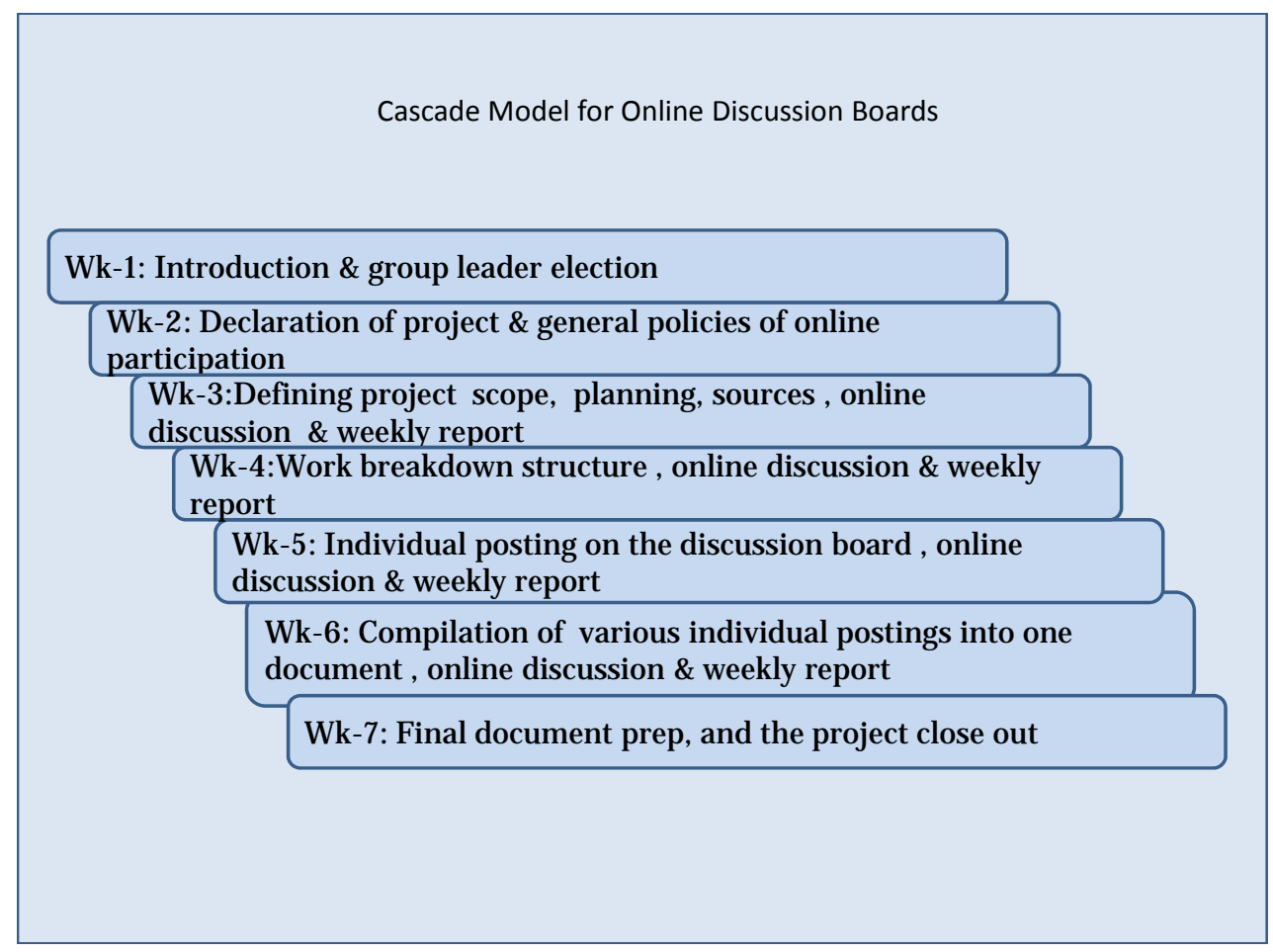

Figure 1. Cascade Model for Online Discussion Boards

clarifies the responsibility of the assigned work, and aligns the subsection of the work assigned for each participant. The weekly report will be posted by the team leader at the end of the week while the e-moderator will set up a thread for the group and intervene to clarify, if necessary.

Week-5 Individual postings on the discussion board, online discussion \& weekly report: Based on the assigned work by the leader, each member will share his/her initial thoughts and searched material on the discussion board, followed by a thorough discussion on the board. The team leader will then post the summary of the week.

Week-6 Compilation of various individual postings into one document: Various important discussion points will be selected and compiled in one document. The discussion on what should be included in the draft of the assignment will be discussed. A report will be posted at the end of the week. The e-moderator will set up a thread for the group and intervene to clarify, if necessary.

Week-7 Final document preparation (editing, refining), power point slides prep, \& close out: The seventh week will be spent on discussing the editions, format, and bibliography of the final document. Any additional preparation, like power point, may be added to the final product. The leader will prepare a final report on the members' participation, collaboration, and cooperation throughout the project and also on the work done by the team members. The e-moderator will set up a thread for the group and intervene to clarify, if necessary. The group leader will post the final document as instructed by the emoderator.

\section{DISSCUSSION}

A five-stage model of e-moderating of the reference [2] has described a broader scope of e-learning and teaching, such as access and motivation, online socialization, information exchange, knowledge construction, and develop- ment. In access and motivation, the key issues for teachers are to welcome and encourage students to gain access to the system, and be motivated for "hand holding" as required. In the second step, they send and receive messages for an online socialization, familiarize, and provide bridges between cultural and social learning. The third stage of information exchange is to search, personalize software, facilitate task and support use of learning materials. The fourth stage include the e-moderator to conference and facilitate the process, wherein participants interact with each other and respond to each others' messages while involving themselves in active learning. In this stage, moderators demonstrate the skills related to group building and maintenance. The final stage is the development phase where participants become responsible for their own learning challenge. Reference [3] discusses shifting of work within the groups, providing a basic framework to assist with self-management, and special characteristics that help groups to manage on-line discussions. This discussion board cascading model of the online course and group project fits in between the fourth and fifth steps of Salmon's five-stage model (Fig.2).

The group project runs separately from the regular weeks of the course, but intermingles and weaves within other regular weeks of the course (Fig.3). For example, if the whole course is of 12 weeks, the group's weekly platforms mesh with the regular weeks starting from week-4 to week-10.

E-moderators can guide students on each step of the given exercise and provide help to the students on weekly cascading group discussion platforms. This format gives a much better outcome, and both parties (students \& emoderator) are satisfied in online learning environment. This cascading model provides an understanding of stepby-step of online project \& group management in higher education. 


\section{CASCADE MODEL FOR ONLINE DisCUSSION BOARDS IN AN E-LEARNING ENVIRONMENT}

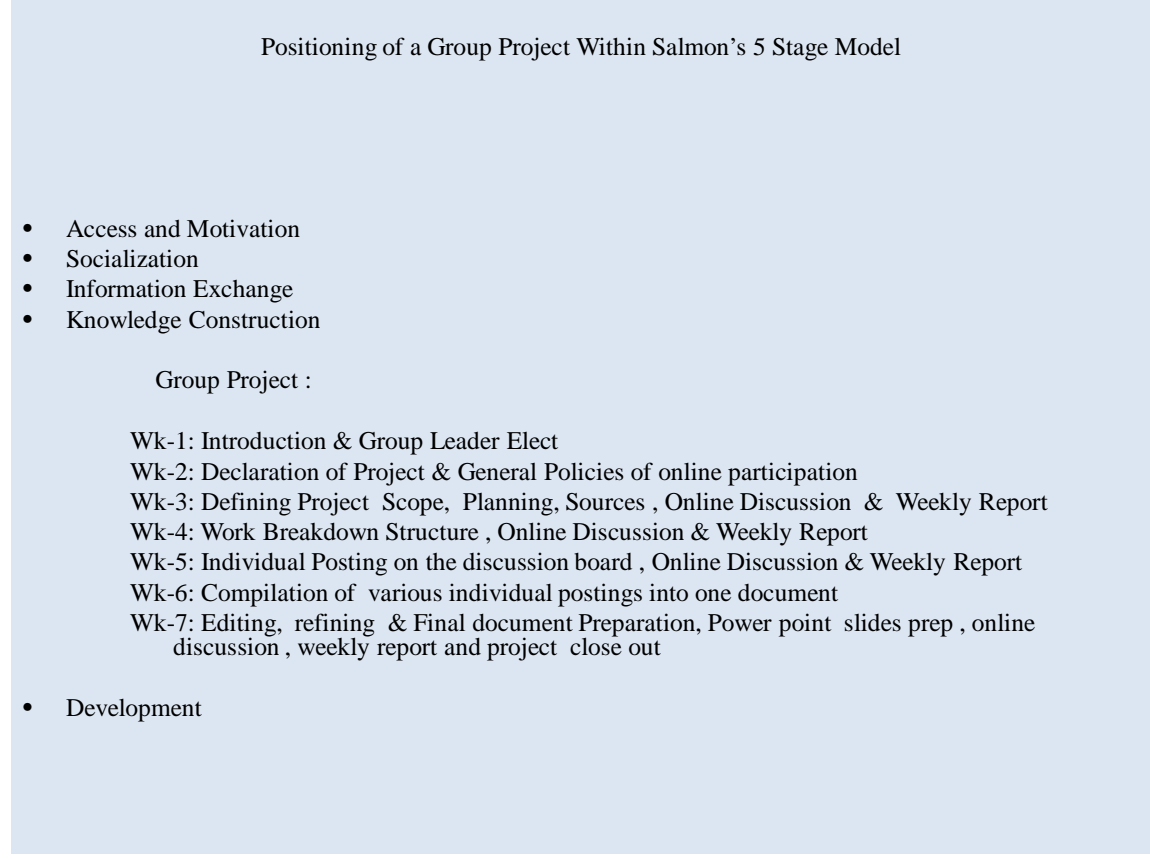

Figure 2. Positioning of the Group Project within Salmon’s 5 Stage Model

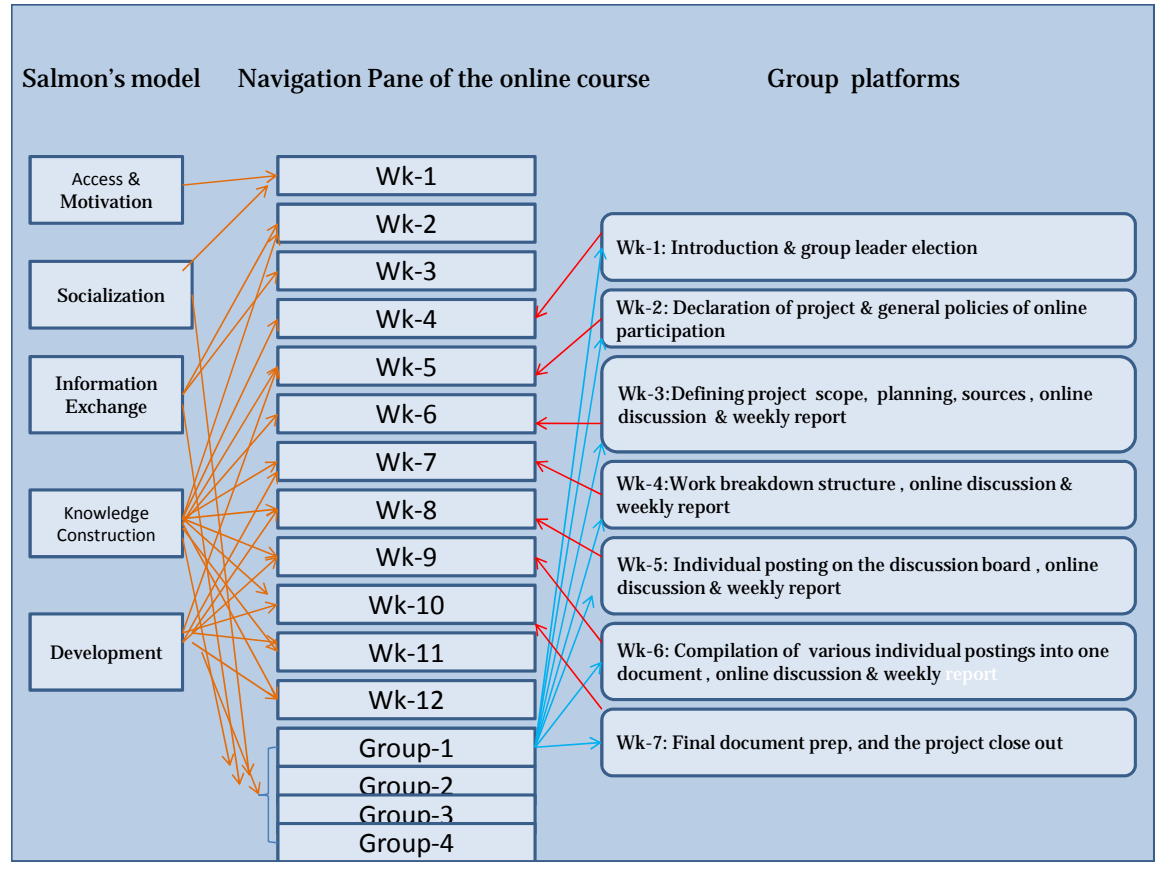

Figure 3. Positioning and Interweaving between Salmon Model \& Cascade Model within a 12-week course

\section{ACKNOWLEDGMENT}

I owe gratitude to Kushi-Nidhi Kumar who pleasantly involved herself in editing this report.

\section{REFERENCES}

[1] Project Management Institute, .A Guide to Project Management Body of Knowledge PMBOK. Newtown Square, Pennsylvania, 2003.Available http://www.unipi.gr/akad_tmhm/biom_dioik_tech/ files/pmbok.pdf

[2] G. K. Salmon, E-moderating: The Key to Teaching and Learning online (2nd edition), London: Routledge Falmer. 2004.
[3] G. Salmon, 80:20 for E-Moderators, UK University Leicester, 2006.Available http://www.ecompetence.info/uploads/media/ ch16.pdf

\section{AUTHORS}

V. Kumar is with the Department of Health Informatics, Medical College of GA, Augusta, GA-30909, USA (email: vikumar@mcg.edu).

Manuscript received 14 January 2010. Published as resubmitted by the authors February 11, 2010. 